\title{
Evaluating the Quality of Life and Social Support in Patients with Cervical Cancer after Treatment
}

\author{
Bualuang Sumdaengrit*, Katekaew Jengprasert and Narumon Sriintravanit \\ Faculty of Medicine, Ramathibodi Hospital Mahidol University, Thailand
}

*Corresponding author: Bualuang Sumdaengrit, Nursing Instructor, Ramathibodi School of Nursing, Faculty of Medicine Ramathibodi hospital Mahidol University, Bangkok, Thailand

submission: September 11, 2018; Published: September 27, 2018

\begin{abstract}
Aims: Purposes of this descriptive correlational research were to 1) describe quality of life and social support and 2) look at the correlation of certain factors and quality of life in women with cervical cancer after treatment.

Methods: Fifty-three women diagnosed with cervical cancer who were followed up after finished the treatments at the Gynecological outpatient department of a university hospital in 2016.They were asked to fill 3 questionnaires; 1) the general information; 2) Social support; and 3) Functional Assessment of Chronic Illness Therapy (FACT-Cervix). Alpha Cronbach's coefficients for the social support was .73 and for the FACT-Cervix was .91. Data were analyzed by descriptive statistic and Spearman Rank Test.
\end{abstract}

Result: Results showed that participants' age was ranged from 30 to 86, mean=55.15 (SD=10.05). Social support was about 29 to 59 , mean=48.23 $(S D=6.76)$. Symptom distress was from 0 to 9, mean=3.36 ( $S D=2.83$ ). For quality of life was diverted from 75 to159, mean=126.02 (SD=21.09). The results discovered that there was no correlation between age and social support with the quality of life, however, there was negative correlation between symptom distress and quality of life with $\mathrm{r}=-.40$ at $\mathrm{p}=0.003$.

Conclusion: This study disclosed that social support for this women's group could not help to improve their quality of life. Their symptom distress seems to have a direct effect on their QOL. Thus, the healthcare team needs to alleviate patients' distress in order to improve the quality of life in cervical cancer survivors.

Keywords: social support; quality of life; cervical cancer; after treatment

\section{Introduction}

Cervical cancer is the second most common cancer in Thai women, as much as it is in other South East Asian counties [1]. The new cervical cancer incidence reported by the Thai National Cancer Institute has been varied from $12.15-15.14 \%$ in the period from 2012-2016 [2-6]. During the past five years, the number of women who survived from cervical cancer has increased significantly as a result of advanced and effective treatments [2-6]. These women have to invest so much effort on coping with the disease and treatment side effects, since diagnosis until treatment is completed. However, there will be remaining symptoms in these women such as fatigue, problems with urination, vaginal dysfunction, anorexia and anxiety [7,8]. These are symptom distress [9] that may have an impact on the quality of life in these cancer survivors. In contrast, during the period-from when these women were diagnosed with cervical cancer until they received treatment-these women normally received a lot of social support [10]. This is because in the Thai culture, cervical cancer patients usually receive emotional and informational supports from their family members and health care providers. In addition, peer support from their friends, and financial support from their family members $[7,8]$ are received as well. These supports may improve patients' quality of life. However, after the cervical cancer treatment is over, these social support starts fading. Even though, they still have the remaining symptoms from the cancer and its treatment. If these patients with cervical cancer receive adequate social support such as emotional, informational, peers, and financial support from their family, these may promote a better quality of life for the cervical cancer patients [9-11]. However, receiving overly, unnecessary support from family members, friends or health care providers could result in negative support, which instead decreases the quality of life of patients.

Other factors such as age [12] and time after treatment of cervical cancer patients may also affect their quality of life. Patients who are older and have been through the treatment a long time might not be affected in their quality of life. Vice versa, younger patients who just have been through the treatment quite recently may have lower quality of life than those who are older and completed treatment long time before them. Social support, symptom distress, age, and time after treatment are factors of cervical cancer patients, which may potentially affect their quality of life. To know what factors are associated with the quality of life in cervical cancer patients after treatment, it is necessary that health care providers reduce symptom distress and promote the social support in cervical cancer patients after treatment (Figure 1). 
Selected factors

-Age

-Symptom distress

-Time after treatment

\section{Social support \\ -Emotional support \\ -Informational support \\ -Peer support \\ -Negative support \\ -Financial support}

Figure 1: Conceptual framework of this study.

\section{Purposes of the Study}

The two key purposes of this research were: 1) To describe the social support and quality of life and 2) To inspect the correlation of particular factors and quality of life of women with cervical cancer after treatment.

\section{Material and Method}

This descriptive correlational research was conducted with convention samples of 53 women with cervical cancer after treatment, who visited the gynecological outpatient clinic at a university hospital between January-December 2016. Sample sizes were calculated by using the correlation sample size from the University of California at San Francisco Training in Clinical Research (TICR) Program access [13]. Then, the power 0.80, alpha 0.05 , with medium correlation $(\mathrm{r}=0.38)$ from the previous study [11] were used to calculate the sample sizes.

\section{Instruments}

There were three instruments used as follows: (1) Personal information and disease related treatment questionnaires; (2) Social Support questionnaires developed by Toljamo and Hentinen [14] and (3) the Functional Assessment of Chronic Illness Therapy (FACT-Cervix) questionnaires-Thai version developed by Cella [15]. The details of these instruments are following described: Personal, disease, and symptom questionnaires were developed by the principal investigator and colleagues. The information attained was: Personal data, disease, and treatment, such as stages of cervical cancer and its treatment, time after treatment, remaining symptoms and symptom distress scale from 0 to 10 .

Social Support questionnaires were originally developed by Toljamo and Hentinen [14], as well as Leelajaras and Orathai [16] and later were translated into Thai and their construction was tested. It is comprised by five subscales assessing social support; emotional, informational, peer, negative, and financial support. There are 12 items with a 5-level likert-scale. The score in each item ranked from 1 (always disagree) to 5 (always agree). There are 10 positive items and 2 negative items. The interpretation of the summed score is attained through the interpretation of each subscale (a high score means high social support). The reliability of the instrument with Cronbach's Alpha Coefficient was 0.73.

The Functional Assessment of Chronic Illness Therapy (FACTCervix) questionnaires-Thai version was developed by Cella [15]. The original instrument was used to assess quality of life in cervical cancer patients. It consists of five subscales of quality of life; physical well-being, social/family well-being, emotional well-being, functional well-being, and specific for cervical cancer. There are 42 items with 20 positive items and 22 negative items. Each item consists of a 5-level likert-scale ranked from 0 (not at all) to 4 (very much). The items in the 5 subscales are distributed as follows: physical well-being 7 items, all of them are negative items; social/ family well-being 7 items, all of them are positive items; emotional well-being 6 items, includs 1 positive item and 5 negative items; functional well-being 7 items, all of them are positive items; and specific to cervical cancer are 15 items, which include: 5 positive items and 10 negative items. The interpretation of the summed score is attained through the interpretation of each subscale (a high score means high quality of life). The reliability of the instrument with Cronbach's Alpha Coefficient was 0.91.

\section{Protection of Human Rights}

The main investigator and their colleagues submitted the study to the Committee on Human Subjects from a university-affiliated hospital, this was done to ensure the protection of human rights before data collection. Then the committees approved the IRB, 
the PI and colleagues began the data collection process. These procedures followed the Helsinki Declaration of 1975, as a revised in 2000, ID 06-56-30, with number MURA 2013/385/NP1.

\section{Data analysis}

Statistical Package for Social Sciences (SPSS) for Windows OS version 21 was used to analyze the data through statistical methods as follows;

A. The personal, disease, and treatment data in cervical cancer patients after treatment was analyzed by descriptive statistic.

B. The overall and 5 subscales corresponding to social support including emotional, informational, peer, negative, and financial support were analyzed by mean, standard deviation, possible and actual range. In addition, the overall and 5 subscales corresponding to quality of life, which are: physical well-being, social/family well-being, emotional well-being, functional well-being, and specific to cervical cancer were

Table 1: Personal characteristic of cervical cancer patients $(n=53)$. also were analyzed using the same statistic methods as social support.

C. The correlation between the selected factors: social support and quality of life, was analyzed by Spearman Rank Test, with the significant level at 05 .

\section{Results}

Results found that the age range of 53 participants was between 30 and 86 years, mean $=55.15(\mathrm{SD}=10.05)$. The average number of years after treatment was 4.57 years $(S D=3.26)$, with the possible range of $0-11$. Majority of cervical cancer patients had partner (67.90\%), and almost all of them were Buddhism (96.20\%). Threefourth of them $(71.70 \%)$ had secondary education level and less. Nearly half of them $(41.50 \%)$ fell into low income range which was less than 10,000 baht/month. Two dominant occupations were government officials (32.10\%) and housewives (32.10\%). Majority of them had sufficient financial status (84.90\%) and were eligible to be subsidized for their treatment by the government $(84.90 \%)$. Data information is shown in Table 1.

\section{Personal Characteristic}

Age (years) mean $=55.15, \mathrm{SD}=10.05, \min -\max =30-86$

$<1$

$1-5$

$>5$

\begin{tabular}{|c|c|}
\hline $\mathbf{N}$ & $\mathbf{\%}$ \\
\hline & \\
& \\
\hline 1 & \\
\hline 31 & 1.90 \\
\hline 21 & 58.50 \\
\hline
\end{tabular}

Marital status

\begin{tabular}{|c|c|c|}
\hline Had Partner & 36 & 67.90 \\
\hline No Partner & 17 & 32.10 \\
\hline \multicolumn{3}{|l|}{ Religion } \\
\hline Buddhism & 51 & 96.20 \\
\hline Christian & 1 & 1.90 \\
\hline Muslim & 1 & 1.90 \\
\hline \multicolumn{3}{|l|}{ Education } \\
\hline Primary & 25 & 47.20 \\
\hline Secondary & 13 & 24.50 \\
\hline Certificate/Diploma & 2 & 3.80 \\
\hline Bachelor & 6 & 11.30 \\
\hline Post graduate & 7 & 13.20 \\
\hline \multicolumn{3}{|l|}{ Income (baht/month) } \\
\hline$\leq 5,000$ & 12 & 22.60 \\
\hline $5,001-10,000$ & 10 & 18.90 \\
\hline $10,001-20,000$ & 11 & 20.80 \\
\hline$>20,000$ & 20 & 37.70 \\
\hline Occupation & & \\
\hline
\end{tabular}




\begin{tabular}{|c|c|c|}
\hline Government official & 17 & 32.10 \\
\hline Housewives & 17 & 32.10 \\
\hline Merchant & 9 & 17.00 \\
\hline Agriculture & 5 & 9.40 \\
\hline Own business & 5 & 9.40 \\
\hline \multicolumn{3}{|l|}{ Financial status } \\
\hline Sufficient and save & 19 & 35.80 \\
\hline Sufficient & 26 & 49.10 \\
\hline Not enough and debt & 8 & 15.10 \\
\hline \multicolumn{3}{|l|}{ Types of payment } \\
\hline Self-payment & 8 & 15.10 \\
\hline Health insurance & 9 & 17.00 \\
\hline Social health insurance & 1 & 1.90 \\
\hline Official government & 35 & 66.00 \\
\hline
\end{tabular}

Results in Table 2 revealed that nearly half of participants had stage II cancer (49\%), followed by cervical cancer stage I and III respectively (26.40 and $24.60 \%$ ). Half of them (50.95\%) received concurrent treatment of radiotherapy and chemotherapy, followed by those who received surgery $(22.60 \%)$ and combined treatment with surgery $(18.90 \%)$. The symptom distress scale varied from

Table 2: Description of cancer, treatment, and remaining symptoms in cervical cancer patients after treatment $(\mathrm{n}=53)$.

\begin{tabular}{|c|c|c|}
\hline Variables & $\mathbf{n}$ & $\%$ \\
\hline \multicolumn{3}{|l|}{ Stage of cervical cancer } \\
\hline I & 14 & 26.40 \\
\hline II & 26 & 49.00 \\
\hline III & 13 & 24.60 \\
\hline \multicolumn{3}{|l|}{ Treatment received } \\
\hline Surgery & 12 & 22.60 \\
\hline Radiotherapy & 4 & 7.55 \\
\hline Concurrent treatment & 27 & 50.95 \\
\hline Combined with surgery & 10 & 18.90 \\
\hline \multicolumn{3}{|c|}{ Symptom distress mean $=3.36, \mathrm{SD}=2.83$, min- $\max =0-9$} \\
\hline No symptom & 18 & 34.00 \\
\hline Mild (1-3) & 6 & 11.30 \\
\hline Moderate (4-6) & 21 & 39.60 \\
\hline Severe (7-9) & 8 & 15.10 \\
\hline \multicolumn{3}{|l|}{ Symptoms* } \\
\hline Fatigue & 13 & 24.50 \\
\hline Problems with urination & 10 & 18.90 \\
\hline Vaginal dysfunction & 9 & 17.00 \\
\hline Anorexia & 8 & 15.10 \\
\hline Bleed per rectum & 4 & 7.50 \\
\hline
\end{tabular}

0 to 9 , mean $=3.36(\mathrm{SD}=2.83)$ with possible range of $0-10$. The most frequent symptom to occur was fatigue $(24.50 \%)$ and was followed by problems with urination (18.90\%), vaginal dysfunction (17.00\%), anorexia (15.10\%), and bleeding per rectum $(7.50 \%)$, respectively. Detailed information is presented in Table 2.

*can answer more than 1 symptom 
Table 3: Descriptive data of social support and quality of life in cervical cancer patients after treatment $(n=53)$.

\begin{tabular}{|c|c|c|c|c|}
\hline Variables & Possible range & Actual range & Mean & SD \\
\hline Social support & $12-60$ & $29-59$ & 48.23 & 6.76 \\
\hline Emotional support & $4-20$ & $7-20$ & 17.09 & 3.89 \\
\hline Informational support & $2-10$ & $4-10$ & 9.04 & 1.36 \\
\hline Peer support & $3-15$ & $4-15$ & 11.15 & 2.60 \\
\hline Negative support & $2-10$ & $2-10$ & 7.18 & 2.17 \\
\hline Financial support & $1-5$ & $1-5$ & 3.75 & 1.30 \\
\hline Quality of life & $0-168$ & $75-159$ & 126.02 & 21.09 \\
\hline Physical well-being & $0-28$ & $8-28$ & 22.08 & 5.97 \\
\hline Social/family well-being & $0-28$ & $2-29$ & 20.42 & 5.19 \\
\hline Emotional well-being & $0-24$ & $5-24$ & 19.39 & 5.11 \\
\hline Functional well-being & $0-28$ & $12-28$ & 21.73 & 4.87 \\
\hline Specific for cervical cancer & $0-60$ & $25-55$ & 42.40 & 6.97 \\
\hline
\end{tabular}

Results in Table 3 demonstrated that social support diverse from 29 to 59 , mean=48.23 ( $\mathrm{SD}=6.76)$, with possible range of 12 60. In addition, the quality of life in these women was wide-ranging from 75 to 159 , mean=126.02 (SD=21.09), with possible series of 12-60. Results uncovered that age and social support had no correlation with the quality of life. However, there was a negative correlation between symptom distress and quality of life with $r=$ -.40 at $\mathrm{p}=.003$. Data information is shown in Table 4.

Table 4: Correlations between age, symptom distress, social support and quality of life in cervical cancer patients after treatment $(\mathrm{n}=53)$.

\begin{tabular}{|c|c|c|}
\hline Variables & $\mathbf{r}$ & $\mathbf{P}$ \\
\hline Age & -0.125 & 0.374 \\
\hline Symptom distress & -0.401 & 0.003 \\
\hline Social support & 0.243 & 0.08 \\
\hline
\end{tabular}

\section{Discussion}

Results of the study revealed that the participants had considerably high social support and quality of life. However, there was no correlation between social support and quality of life. These results were incongruent with a previous study [11]. This previous study found that social support had a high positive correlation with the quality of life in breast cancer patients after treatment, but it did not correlate with the quality of life in cervical cancer patients in this study. This would mean that these cervical cancer patients did not require any emotional, informational, peers, negative, or financial supports from health care providers or their family members, since the treatment had already been completed. Because, after treatment, women with cervical cancer were still able to participate in physical activities, socialize with friends and family members, and utilize their bodies normally. The cervical cancer patients may not need that much social support as breast cancer patients. However, there was a significant negative relationship between symptom distress and quality of life. The result were congruent with the previous study [9]. This was the result of remaining symptoms although the treatment was completed. It was basically the stigma from cancer and treatment. Health care providers should assess the distress from symptom and help them relieving those remaining symptoms. Thus, even though the cancer has disappeared, the remaining symptoms should be paid close attention to improve patient's quality of life after cancer treatment.

On the other hand, the results from this study demonstrated that age and time after treatment were not correlated with the quality of life. The result was incongruent with previous studies $[9,12]$. Because, according to the data used in this study, women with cervical cancer were in the same middle age group. In addition, the majority of them had a number of years after treatment in the same period. As a result, there was no correlation between age and time after treatment with the quality of life in women with cervical cancer after treatment. Findings from this study confirmed that the symptom distress left after cancer treatment should be the highest concern for health care providers to be relief. The symptoms-which include fatigue, problems with urination, vaginal dysfunction, anorexia, bleeding per rectum or vagina, etc. -should be closely evaluated. Hence, a symptom management program should be constructed and implemented among cervical cancer patients. This kind of intervention may improve quality of life for those women who survived cervical cancer.

\section{Conclusion}

It can be summarized that symptom distress had a negative high correlation with the quality of life in cervical cancer patients after treatment. Nurses and other health care practitioners must be concerned about symptom management in order to reduce any symptom distress in cervical cancer patients after treatment in order to improve their quality of life.

\section{Acknowledgement}

The authors gratefully thank the participants participating in this study and Faculty of Medicine Ramathibodi Hospital, Mahidol University for funding support for this study. 


\section{References}

1. https://gco.iarc.fr/

2. http://www.nci.go.th/th/File_download/Nci\%20Cancer\%20Registry/ Hospital-Based\%20NCI\%202012\%20Total.pdf

3. http://www.nci.go.th/th/File_download/Nci\%20Cancer\%20Registry/ HOSPITAL-BASED\%202013.pdf

4. http://www.nci.go.th/th/File_download/Nci\%20Cancer\%20Registry/ HOSPITAL-BASED\%202014.pdf

5. http://www.nci.go.th/th/File_download/Nci\%20Cancer\%20Registry/ HOSPITAL-BASED\%202015.pdf

6. http://www.nci.go.th/th/File_download/Nci\%20Cancer\%20Registry/ Hospital-Based\%20NCI2\%202016\%20Web.pdf

7. Prasongwej $\mathrm{P}$, Nanthakomon $\mathrm{T}$, Jaisin $\mathrm{K}$, Chanthasenanont $\mathrm{A}$, Lertvutivivat $S$ et al. (2017) Quality of life in cervical cancer survivors and healthy women: Thai urban population study. Asian Pac J Cancer Prev 18(2): 385-389.

8. Pfaendler KS, Wenzel L, Mechanic MB, Penner KR (2015) Cervical cancer survivorship: Long-term quality of life and social support. Clinical Therapeutics 37(1):39-48.

9. Limthongkul M, Sumdaengrit B (2015) Social support and quality of life in breast cancer patients after treatment in university hospital: A comparative study. Rama Med J 2015; 38: 20-28.

10. Nazik E, Nazik H, Ozdemir F, Soydan S (2014) Social support and quality of life in Turkish patients with gynecologic cancer. Asian Pac J Cancer Prev 15(7): 3081-3086.

11. Heepjinda P, Junda T, Sumdaengrit B (2014) Sense of coherence, social support and quality of life among patients with breast cancer post treatment. Thai Cancer J 34: 92-103.

12. Sumdaengrit B, Limthongkul M (2014) Factors predicting quality of life in breast cancer patients after treatment in university hospital. Journal of Nursing and Health Care 32: 85-93.

13. Hulley SB, Cummings SR, Browner WS, Grady D, Newman TB (2018) Designing clinical research: An epidemiologic approach (4 $4^{\text {th }} e d n$ ). Philadelphia, PA: Lippincott Williams \& Wilkins 2013. Appendix 6C, p. 79

14. Toljamo M, Hentinen M (2001) Adherence to self-care and social support. J Clin Nursing 10(5): 618-627.

15. Cella DF (1994) Quality of life: Concepts and definition. J Pain Symptom Management 9(3): 186-192.

16. Leelajaras S, Orathai P (2011) Construct validity of social support questionnaires in Thai women diagnosed with hypertension. J Public Health Nursing 25:1-17.

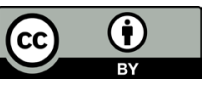

Creative Commons Attribution 4.0

International License

For possible submissions Click Here

\section{Submit Article}

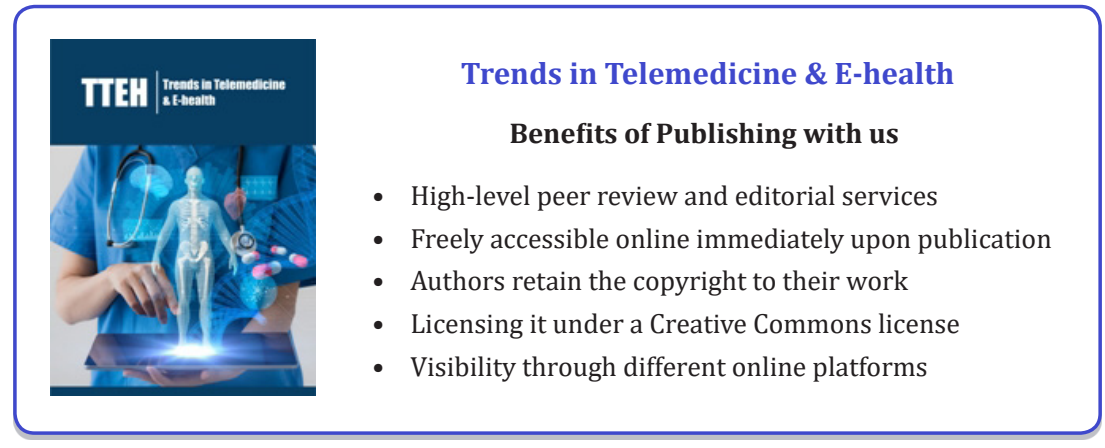

